\title{
A CASE STUDY OF GENERATION Z'S INFORMATION SHARING ON SOCIAL NETWORKING SITES: A SURVEY OF COLLEGE STUDENTS IN HAINING CITY
}

\author{
Li-Wei Lin ${ }^{1}$, Huei-Ping Chen ${ }^{* 2}$ 四 \\ ${ }^{1}$ School of Information, Zhejiang University of Finance and Economics Dongfang College, Zhejiang, \\ China \\ *2 Department of Animation and Game Design; Bachelor's Degree Program on Esports \\ Management, Shu-Te University, Taiwan
}

DOI: https://doi.org/10.29121/ijetmr.v8.i3.2021.876

Article Citation: Li-Wei Lin, and Huei-Ping Chen. (2021). A CASE STUDY OF GENERATION Z'S INFORMATION SHARING ON SOCIAL NETWORKING SITES: A SURVEY OF COLLEGE STUDENTS IN HAINING CITY. International Journal of Engineering Technologies and Management Research, 8(3), 16.

https://doi.org/10.29121/ijetmr.v8 .i3.2021.876

Published Date: 06 March 2021

Keywords:

Perceived Messaging

Decision Making

Social Networking

Spindle Coding

Consumer Loyalty

\section{ABSTRACT}

The purpose of this study is to investigate the information of Generation Z college students who shop on social networking sites. Through in-depth interviews, we investigated whether young people would be influenced by the information on the website. We do triangulation verification through different people, mainly to explore the information views and final decisions of the Generation $\mathrm{Z}$ group on social network websites. Through in-depth interview, we designed the correlation among spindle coding, correlation matrix and reliability and validity. Our research mainly discusses the Gen $\mathrm{Z}$ college students' views on the information on social network websites, and whether they will make shopping and decision-making actions based on the information perceived by the websites, so as to further achieve the effect of consumer loyalty.

\section{INTRODUCTION}

The purpose of this study is to explore whether Gen $\mathrm{Z}$ youth are influenced by the correctness of information on social networking sites and their subsequent decisions.

In our research, we found that Gen $\mathrm{Z}$ is different from the traditional generation in that they are no longer particularly likely to trust messages, information, and ideas of their own on the Internet. Such studies have broken the traditional community commerce, the traditional e-commerce we can found that community workers believe that the information on the Internet and information, and now the $\mathrm{Z}$ generation no longer representatives have such idea, have self awareness, thinking and judging model, a series of business process is a kind of generation $\mathrm{Z}$ community.

Oliver(1997) proposed that satisfaction refers to consumers' feelings of consumption. If the feeling of consumption is continuously positively affected, it will indirectly affect the loyalty of consumers. When consumers 
shop on the Internet, they attach importance to the relationship of trust between the buyer and the seller, which is one of the key factors influencing the establishment of consumer loyalty. Garbarino and Johnson (1999) proposed that loyalty refers to consumers' views on the loyalty of buyers and sellers. From the above arguments, we can clearly understand the importance of their loyalty in the minds of consumers. In recent years, the rapid changes in the Internet era have made it more and more difficult for manufacturers and consumers to maintain loyalty. Because, as long as a consumer has been stimulated by the outside world, it may lead to its loyalty to produce its change. In particular, Generation Z young people in Taiwan are more likely to be influenced by new products from the outside world and quickly change their loyalty to the original product. Shoemaker and Lewis(1999) point out that consumer loyalty consists of three concepts: service process, value creation and communication.

The most important key factor in sharing information on social networking sites is correctness. With the development of information network, the information on the network needs a lot of interpretation. Is it correct? With the development of Internet information, information needs to be more accurate in the analysis of consumers in the process of information transmission. Information in the community, the perception of consumers, is related to word of mouth. Oliver(1997) proposed that cognitive loyalty, in the process of purchasing products, consumers will influence their decision-making by associating with the brand. Therefore, the perception information of consumers becomes one of the variables to be studied in this study. Through its perception information, we can investigate whether it has its influence on consumer loyalty.

Consumers' perceived information may be transmitted through messages on social commerce platforms (including messages, instant message interaction, etc.), and a series of uncertainties will influence consumers' decision-making. We should further observe whether their consumer loyalty will change. Xiao Xiyuan (2008) proposed that the better the brand image, the more it can enhance the perceived value of its consumers. Therefore, consumer perception will be affected by the brand position of the outside manufacturer. Sweeney and Soutar(2001) proposed that perceived value is influenced by its perceptual and social values. Wondruff(1993) proposed the combination of consumer perceived value and satisfaction in product experience. From the above concepts, we can clearly understand that perceptual information is an important factor for consumers. On the other hand, we have also found out whether the information in the community will have an impact on the young people of Generation Z, which is worth directly exploring and studying in this study.

In this study, the information stimulus is included in the design change, whether the information stimulus will lead to the change and change of consumer satisfaction. This has something to do with the rapid change of social networking sites. If a social networking site provides a better service, whether consumers will be influenced by the stimulus of messages on their loyalty.

Mostafa(2007) proposed that personal beliefs and values can influence users' decision-making views. Therefore, the beliefs of the platform determine its key concepts through the thinking of the entire individual, especially the modern Gen Z youth. Many journals refer to the concept of faith, and traditional research suggests that what we know about faith is applied through informational trust. In order to observe the views of the young people of Generation Z, we mainly conducted a survey on the young college students aged 20-24 in Haining, hoping to find out their different views and ideas and further break their traditional research methods and models.

\section{LITERATURE REVIEW}

In recent years, there has been a lot of literature on the relationship between brand loyalty and consumer loyalty. The purpose of this study is to look into the relationship between the communities of the whole community business through their consumer loyalty.

Yoo, Donthu, and Lee(2000) measured three dimensions, namely brand awareness, perceived quality, and brand equity ownership. It can be seen that the three dimensions are correlated with consumer loyalty.

Karrh (2003) put forward the important concept of generating positive consumer response and reaction. Therefore, how consumers in social commerce are recognized and recognized is one of the key factors. Perceived value is often mentioned in psychology and consumer behavior. Perceived value represents a person's identity and idea, which can bring its value after continuation. This series of processes becomes perceived value. Yoon, Choi, Song (2011) mentioned that consumers' perception can be understood by systematically sorting out their cognitive resources and motivations. Passa et al.(2003) mentioned the idea that we should focus on cognition. From the above discussion, we can clearly understand the concept that perceived value is very important for social business users 
to interpret their information sharing. Will users identify with your social business? This is why we use the perceived information value factor to discuss the content of the article.

The purpose of this study is to investigate the generation $\mathrm{Z}$ college students in Haining, and to observe and analyze whether they are influenced by the materials and information on social commerce websites. Through its research design, we mainly observe the relationship between the causative variables and the effectual variables.

\section{RESEARCH METHOD}

Based on the design of three hypotheses, the main purpose of this study is to do exploratory research, hoping to verify and analyze whether their hypotheses have significant correlation and difference through the analysis of hypothesis verification. Through the design of hypothesis test, whether perceptual information, belief, and information stimulation are correlated with consumer loyalty. The hypothesis testing of this study is as follows:

H1: Whether there is significant difference between perceived information and consumer loyalty

H2: Whether there is a significant difference between belief and consumer loyalty

H3: Whether there is a significant difference in the loyalty of consumers to information stimulation

The biggest purpose of this study is to test the relevance of the three hypotheses, mainly to find out whether Generation $\mathrm{Z}$ will be affected by information to purchase decisions, and ultimately to find out their research contributions.

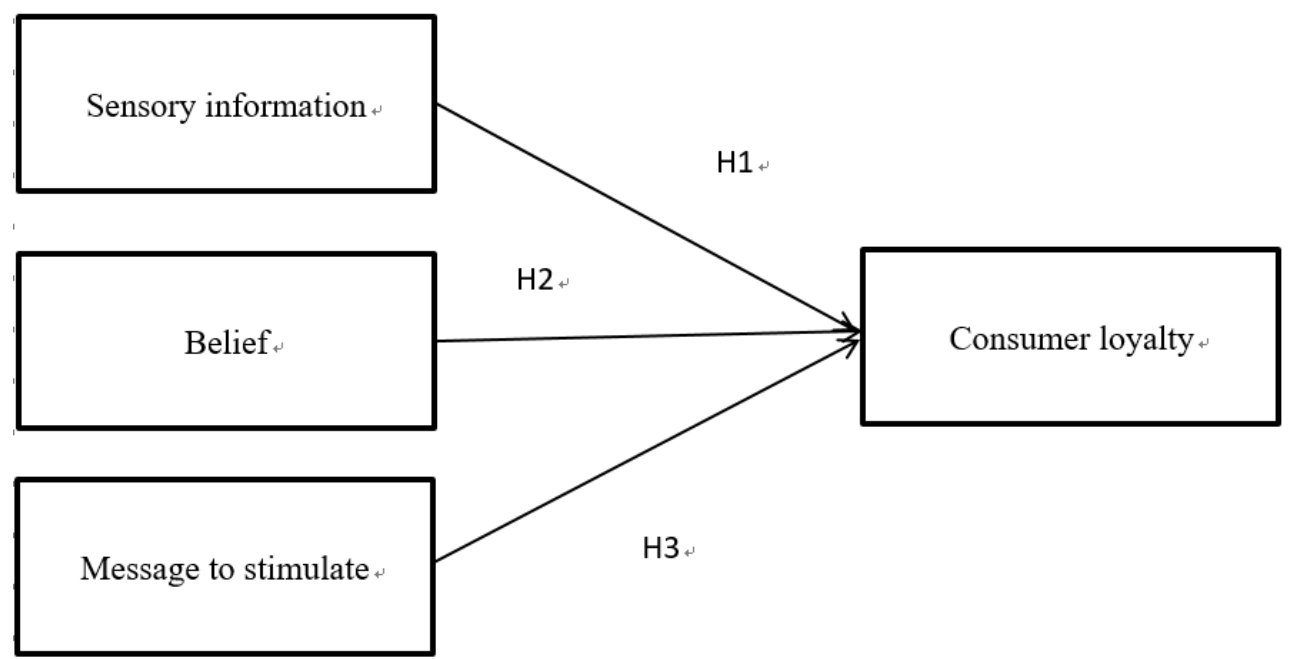

Figure 1: Research model

\section{DATA ANALYSIS}

In this study, the case interview method was used to investigate its reliability. Through the interview codes of two times, we can clearly see that its reliability is greater than 0.7. We mainly want to investigate its correlation through its investigation. The preliminary study design of this study investigated the relationship through triangulation. Reliability represents the consistency and stability of measurement results. The table below Cronbach's $\alpha$ is the statistical table of reliability obtained by triangulation verification.

\section{CONCLUSION}

It can be found that perceptual information, belief and information stimulation have significant influence on consumer loyalty. Therefore, we can clearly understand the overall effect of causality. Therefore, it is clear that hypothesis 1, hypothesis 2 and hypothesis 3 have a significant relationship.

Therefore, we can get the whole data and analyze the results through in-depth interview, so that we can clearly see the causal logical relationship. Through such a coherent design, we can see whether the correlation is valid. The 
sample size of this study was $\mathrm{N}=128$, and the correlation was observed through individual interviews. Through the interview process, it can be clearly seen that its reliability reaches 0.9 . Our ultimate goal is to verify the whole model through the establishment and analysis of such a hypothesis model.

We design the research structure, content and methodology through a rigorous design, and ultimately hope to be able to produce the results of the analysis of the research hypothesis. The greatest contribution of this study is to fill in the research related to community business. The Gen $\mathrm{Z}$ survey is a topic that no one in the academic circle has studied anymore. The research of community business focuses on the relationship between its buyers and sellers, while our research is a combination of interdisciplinary research, such as psychology, behavioral science, and international trade. The ultimate purpose of such research design is to find out the research on their perceived message, belief and message loyalty to consumers.

The biggest limitation of this study is that it only targets students in Haining, China. Due to the lack of time and energy, the research is very challenging. The qualitative in-depth interview research of this study is mainly conducted in line with the emerging changes of community business in mainland China, which is innovative in the research of community business.

\subsection{RESEARCH IMPLICATIONS}

The purpose of this study is to respond to the measurement of the performance of the community business model. We are mainly trying to fill the gap in the existing e-commerce research on social commerce, which rarely studies the performance of social commerce enterprises and consumers in the transaction process and mechanism establishment of their business model.

The impact of the concept of social business on consumer loyalty was confirmed by this study. Namely, Haining college students can cause with its influence on customer loyalty, this research mainly questionnaire distributed objects is the Haining university students to do their investigation into mainland China, but in the process of investigation, vendor for community business idea of college students, has broken the traditional think virtual shopping on the site as long as both sides of the trust relationship, can easily obtain relevant further shopping. However, in the process of research, information stimulation is included in the questionnaire design, the main purpose of which is to obtain the views and thoughts of Haining college students about information on the Internet. We suggest that future research can conduct in-depth interviews for college students in other provinces in mainland China, so as to have objectivity and reduce errors in the questionnaire survey.

We further explore the impact of social business messages on business model performance. Our research mainly focuses on some Gen Z young people's views on sharing information with friends on the Internet. It can be found that Gen Z young people have their own opinions. Unless Gen Z is exposed to more stimulating information from the outside that causes them to change their decisions.

The results of this study can also be extended for further research and analysis. It is suggested that future researchers can investigate manufacturers in different countries and overseas consumers. Although we take college students in Haining as the objects of investigation, due to the regional relationship, we cannot directly and practically investigate the situation of community business in other regions of China.

\subsection{PRACTICAL IMPLICATIONS}

The research of this paper can respond to the current situation of social commerce and the suggestion of consumer loyalty between messages. First of all, this study is one of the few who will study the concept of Gen $\mathrm{Z}$ in community business, and few people in practical studies around the world will study the concept of Gen $\mathrm{Z}$ in community business. Studies have shown that Gen Z, for example, have an independent view of their use of social commerce and are less likely to trust information provided on the Internet. We investigate the concept of information in community business to test whether the Haining Generation $\mathrm{Z}$ youth are influenced by the information generated by their consumer loyalty.

\subsection{FUTURE RESEARCH DIRECTION}


It is suggested that subsequent researchers can construct their innovative variables in the design and research framework. This study has made a preliminary design and planning investigation in the field of new social business, but due to the lack of human, material and financial resources, it is unable to conduct in-depth investigation and discussion. In the process of this study, there are two main limitations. The first point is that it is difficult to collect the data of college students in Haining in the process of questionnaire collection, because the community business needs to conduct in-depth interviews in the process of survey, and some college students are not willing to survey in the process of interview, so it needs to spend a lot of time on the survey. The second point is that the social business aspect can make the action of information integration in the future, because the social business will have the different opinion and thought according to the different age group, it is suggested that the following researchers can design the name variable more strictly.

Finally, this paper suggests that the model of community business can be used to consider different innovation variables in the future scale, and further details can be added through the shortcomings of this study, so that the whole study can be more perfect.

Table 1: The first time to code the reliability statistics table

\begin{tabular}{|c|c|c|}
\hline The researchers & Researcher code & The total number of coding \\
\hline A & R1 & 66 \\
\hline B & R2 & 53 \\
\hline \multicolumn{2}{|c|}{ Total } & 109 \\
\hline \multicolumn{2}{|c|}{ Common } & 45 \\
\hline \multicolumn{2}{|c|}{ Reliability } & 0.756 \\
\hline
\end{tabular}

Table 2: The second encoding reliability statistics table

\begin{tabular}{|c|c|c|}
\hline The researchers & Researcher code & The total number of coding \\
\hline A & R1 & 66 \\
\hline B & R2 & 62 \\
\hline \multicolumn{2}{|c|}{ Total } & 128 \\
\hline \multicolumn{2}{|c|}{ Common } & 58 \\
\hline \multicolumn{2}{|c|}{ Reliability } \\
\hline \multicolumn{2}{|c|}{} \\
\hline
\end{tabular}

\section{SOURCES OF FUNDING}

This research received no specific grant from any funding agency in the public, commercial, or not-for-profit sectors.

\section{CONFLICT OF INTEREST}

The author have declared that no competing interests exist.

\section{ACKNOWLEDGMENT}

None.

\section{REFERENCES}

[1] Xiao Xiyuan (2008). The influence of brand image and perceived value on brand loyalty: a case study of $85^{\circ} \mathrm{C}$ coffee chain. Advanced Master of Management of Evergreen University Master of Thesis in Vocational Class.

[2] Garbarino, E. and Johnson, M.S. (1999), "The different roles of satisfaction, trust and commitment in customer relationships," Journal of Marketing, 63(April), 70-87.

[3] Karrh, James, Kathy B. McKee, and Carol J. Pardun (2003),Practitioners Evolving Views on Product Placement Effectiveness, Journal of Advertising research 43(2), 138-49. 
A Case Study of Generation Z's Information Sharing on Social Networking Sites: A Survey of College Students in Haining City

[4] Mostafa, M.M.(2007). A hierarchical analysis of the green consciousness of the Egyptian consumer. Psychology\&Marketing,24(5),445-473.

[5] Oliver, R.L. (1993), "Cognitive, affective, and attribute bases of the satisfaction

[6] response," Journal of Consumer Research, 20(3), 418-430.

[7] Oliver, R.L. (1997),Cognitive model of the antecedents and consequences of satisfaction decisions," Journal of Marketing, 17(November), 460-469.

[8] Paas, Fred, Juhani E. Tuovinen, Huib Tabbers, and Pascal W.M. Van Gerven(2003), "Cognitive Load Measurement as a Means to Advance Cognitive Load Theory," Educational Psychologist, 38 (1), 63-71.

[9] Shoemaker, S. and R.C. Lewis(1999). Customer Loyalty: The Future of Hosipitality Marketing. International Journal of Hospitality Management,18(4),.345-370.

[10] Sweeney, J.C. and Soutar(2001),G.N.(2001).Consumer perceived value: the development of a multiple item scale. Journal of Retailing,77,230-220.

[11] Wondruff, R.B. Schumann, D.W. and Gardial, S.F.(1993). Understanding value and satisfaction from the consumers point of view. Survey of Business,29(3),33-40.

[12] Yoon, Sukki, Yung Kyun Choi, and Sujin Song (2011), "When Intrusive Can Be Likeable: Product Placement Effects on Multitasking Consumers," Journal of Advertising, 40 (2), 63-75.

[13] Yoo and Donthu(2001).Developing and validating a multidimensional consumer-based brand equity scale. Journal of Business research.52.1-14. 